\title{
Effluent standards for developing countries: combining the technology- and water quality-based approach
}

\author{
A.M.J. Ragas ${ }^{1}$, P.A.G.M. Scheren ${ }^{2}$, I. Konterman ${ }^{2}$, R.S.E.W. Leuven ${ }^{1}$, P. Vugteveen ${ }^{1}$, H. Lubberding ${ }^{3}$, \\ G. Niebeek ${ }^{4}$ and P. Stortelder ${ }^{4}$ \\ ${ }^{1}$ Department of Environmental Studies, University of Nijmegen, P.O. Box 9010, 6500 GL Nijmegen, \\ ${ }^{2}$ Royal Haskoning, Nijmegen, \\ ${ }^{3}$ UNESCO-IHE, Institute for Water Education, Delft, \\ ${ }^{4}$ RIZA, Institute for Inland Water Management and Wastewater Treatment, Lelystad, \\ The Netherlands
}

Keywords: effluent standards; environmental quality objectives; water quality

\begin{abstract}
In many developing countries the definition of effluent standards is poor. They are either too stringent because they are based on standards from developed countries, or too relaxed and therefore not guaranteeing the safe intended uses of water. In order to define an approach for setting effluent standards that suits the needs and means of developing counties, water quality management practices in the USA, the EU, the New Independent States (NIS) and the Philippines were analysed and compared. Four criteria (protection of the environment, technical viability, economic feasibility and institutional capacity requirements) were used to assess the suitability of these practices for developing countries. It is concluded that a combined approach that is based on Environmental Quality Standards (EQSs) and Best Available Technology Not Entailing Excessive Costs (BATNEEC) is the best way to define effluent standards that restrict water pollution, against affordable costs.
\end{abstract}

\section{Introduction}

Water is inextricably bound up with live. As confirmed by the recent World Summit on Sustainable Development in Johannesburg (United Nations, 2002), the availability of clean water is one of the most crucial factors in human development. The general objective of Agenda 21 (United Nations, 1992) with respect to freshwater is: "...to make certain that adequate supplies of water of good quality are maintained for the entire population of this planet, while preserving the hydrological, biological and chemical functions of ecosystems, adapting human activities within the capacity limits of nature and combating vectors of water-released diseases."

Several studies have shown that pollution levels tend to rise with increasing development, until development generates enough wealth to promote significant pollution control. This inverted-U-shaped relationship between per capita income and pollution is known as the Environmental Kuznets Curve (EKC; Grossman and Krueger, 1992; Rothman and De Bruyn, 1998). For many developing countries, the end of the pollution growth does not yet seem in sight, and it might take considerable time before sufficient revenues are generated for efficient pollution control. To prevent such scenario, new and creative solutions are needed to reduce pollution levels and protect water quality in developing countries.

A possible means for controlling water pollution is through defining, applying and enforcing effluent standards for waste water discharges (Konterman et al., 2003). Most developing countries nowadays apply a set of effluent standards. In many cases, such standards are copied from more developed countries. Given the unfavorable economic conditions prevailing in most developing countries, the costs associated with applying such stringent effluent standards often exceed the level of affordability. In other cases, effluent standards are set too relaxed, and do not guarantee the safe intended uses of the water body. Also, the institutional capacity to implement and control effluent standards is often inadequate. As a result, the effluent standards are not enforceable. It is therefore of importance to adopt an approach that is appropriate in terms of protection of water quality, economically and financially affordable and which takes into account available institutional capacity.

The Program Partners for Water of the Dutch Ministry of Transport, Public Works and Water Management initiated a study to develop an efficient strategy for setting effluent standards that would restrict environmental risks to a maximum, against affordable cost (Konterman et al., 2003). The present paper outlines the results of this study, the approaches underlying the definition of effluent standards, followed by an analysis of the technical, economic, and institutional/regulatory considerations involved in such. The analysis is illustrated by a summary of current water management practices in the European Union, the United States, the New Independent States (NIS) and the Philippines. The suitability of these practices for developing countries is evaluated against four criteria: environmental protection, technical viability, economic feasibility and institutional capacity 
requirements. Finally, a strategy for deriving effluent standards is presented that is suited to the means and needs of developing countries.

\section{Approaches in pollution control}

There are two fundamentally different ways to control environmental pollution, i.e., based on the pollution prevention principle and the carrying capacity principle (Ragas, 2000). The prevention principle presupposes that all environmental pressure is potentially harmful and should therefore be prevented whenever possible. It results in standards that are based on what is technologically possible and socioeconomically feasible. The carrying capacity principle presupposes that the environment can cope with a certain amount of pollution. The challenge is to limit the pollution to a level at which no adverse effects occur. Both principles are reflected in two different approaches to set effluent standards:

- The technology-based approach focuses on prevention and reducing emission at the source (i.e. pollution prevention principle), using the best technical and practicable means available. The section Emission Limit Values describes some types of application.

- The environmental quality objective based approach (or EQO-based approach) is based on the impact of the discharge on the quality of the receiving water body (i.e. carrying capacity principle). The approach comes down to predicting future water quality, comparing it with the EQSs (see section Environmental Quality Standards), and if they are expected to be exceeded, deriving effluent standards.

The relationship between the technology- and water quality-based approaches has been subject of considerable international debate (Jirka and Summer, 1992; Stortelder and Van de Guchte, 1995; OECD, 1996; Kraemer, 1996). Both approaches were first considered to be alternative, but there now is a clear tendency to consider them complementary. In this combined approach, the effluent standards resulting from the technology-based approach are often considered minimum requirements and additional restrictions are imposed when EQSs are not met. In practice, most countries in Western Europe and the United States already more or less combine the technology-and EQO-based approaches in their assessment of wastewater discharges to surface waters. Under the European Water Framework Directive (WFD; EU, 2000), the combined approach is advocated (Konterman et al., 2003).

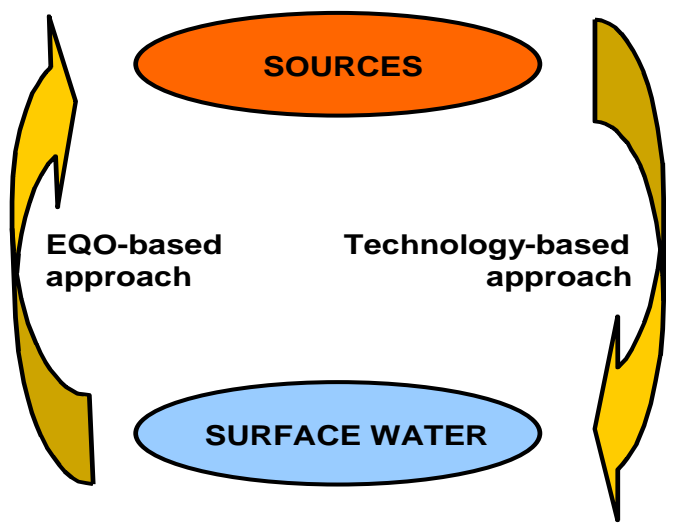

Figure 1. Schematic presentation of the relationship between the technology-and EQO-based approaches.

\section{Technical viability}

Both approaches for controlling point source discharges to surface waters rely predominantly on

Emission Limits Values (ELVs) or discharge limits based on Environmental Quality Standards (EQSs). Whereas both are applied as "end of pipe" controls, ELVs are ultimately derived on the basis of available technologies to reduce emissions with little regard for the biological impacts of those measures. EQSs, on the other hand, are based on the ecotoxicological effects of chemicals and define concentrations below which no adverse effects may be expected (Whitehouse, 2001). Both types of standards are discussed in more detail below. 


\section{Emission Limit Values}

Most technology-based effluent regulations discriminate between different types of point sources. For each point source category, a separate set of effluent standards or regulations is specified. These standards are commonly expressed as Emission Limit Values (ELVs). This implies that extensive knowledge of production processes and wastewater treatment techniques is required to derive technology-based effluent standards.

ELVs are applied to related industries and are usually expressed as legally binding minimum standards in permitting. They may be expressed either as a chemical concentration in the final effluent, or as a pollution load (mass) discharged per unit of time or production. Alternatively, they may be expressed as a specification of the wastewater treatment technology to be applied. Significantly, ELVs are derived on the basis of what can be achieved through the application of "Best Available Technology" (BAT). Although the term Best Available Technology implies that effluent standards are solely based on what is technologically possible, economical considerations often play an important role in the prescription of BAT standards. Terms like Best Practicable Means (BPM) or Best Available Technique Not Encompassing Excessive Costs (BATNEEC) explicitly express the involvement of economical considerations. Furthermore, it should be realized that technology-based effluent standards reflect a certain timeframe. As time advances, new and better treatment technologies become available. This implies that technology-based standards should be updated on a regular basis.

Technology-based effluent standards can differ considerably between regulatory agencies. To illustrate this, Figure $2 a$ shows the results of a case study that compares maximum permissible pollutant loads for a plant processing 1,000 tons of cadmium per year for the production of cadmium sulphide pigment, applying the technology-based regulations of the UK, USA, Germany and the EU, respectively. The differences run up to a factor of 10 . These differences can mainly be explained by a different valuation of economical considerations and the age of the regulations (Ragas and Leuven, 1999).

\section{Environmental Quality Standards}

The aim of setting EQSs is to protect or safeguard water quality with regard to its different functions (bathing water, drinking water production and fishery). For example, a minimum water quality can be defined for all water bodies and more strict EQSs may be imposed for protection of specific functions. An EQS indicates a quality level that should minimally be maintained to prevent unacceptable adverse impacts on the water system. It is a quantitative specification of an abstract policy goal like "sustainable development" or "the protection of human health and ecosystems". An EQS can take various forms, for example a concentration level, a biological integrity indicator or a measure of toxicity. Important for definition is a clear spatial specification (Haans et al., 1998), i.e. to which part of the water body the EQS applies. Omission will limit its administrative implementation (Jirka et al., 2004).

Technical implementation of EQSs in the water quality management process involves two important stages (DCIW, 2000):

1. Quantifying EQOs into a tangible set of Environmental Quality Standards (EQS);

2. Defining effluent standards for individual discharges based on EQSs, through what is often referred to as an immission assessment.

\section{Step 1: Defining EQSs}

The first step in the derivation of EQSs is the establishment of the desired protection level for the subjects and resources that need to be protected against the adverse impacts of water pollution (e.g., humans, ecosystems, specific species or certain functions like the production of drinking water). This step involves various normative choices and therefore belongs to the area of politics. Differing choices may result in differing EQSs. Among location and ecosystem specific considerations, this is an important reason for differences in EQSs between countries (Haans et al., 1998; Ragas, 2000). Once the protection levels are established, the actual EQSs can be derived. This step is primarily scientific in nature. The aim is to relate the presence of water pollution to the manifestation of adverse effects in the water system. For each of the protected subjects and resources, separate EQSs should be derived. Consequently, these can be integrated into a set of EQSs that protects all the subjects and resources. In practice, EQSs are often based on the assignment of functions to (parts of) the water system, whereby separate sets of EQS may be defined for water bodies used for bathing, drinking 
water production and for fishery, or for water bodies with particular ecological values. Furthermore, it is noted that, in many cases, a limited availability of time and resources necessitate a water quality manager to set priorities, whereby priority should be given to those policy measures that improve the water quality in the most efficient way. Such prioritization determines important choices such as the number and type of substances for which standards are set, as well as the complexity of techniques used for water quality management, including defining and monitoring the EQS's (Ragas, 2000; Scheren et al., 1998, 1999 \& 2004).

\section{Step 2.: Immission assessment}

The main aim of an immission assessment procedure is to safeguard that wastewater discharges do not impair the quality of the receiving water body in an unacceptable way. It comes down to predicting future water quality based on current level of pollution and future control measures, comparing it with environmental quality standards (EQSs) and, if necessary, deriving additional emission limits (ELVs). Figure 3 is a schematic presentation of an immission assessment procedure. The basic ingredients are (1) EQSs, (2) a water quality model, and (3) input data. The core of the immission assessment procedure is the water quality model. This model can be anything in between a simple set of calculation rules and a complex computer model (Ragas et al., 1997). It uses the data on the receiving water body, the projected discharge and other discharges to predict the (future) water quality. This predicted water quality (PWQ) is then compared with the available EQSs. If they are exceeded, the future water quality is considered unacceptable and additional emission limits should be imposed on the discharge. The calculations of the water quality model are reversed to derive effluent standards that are compatible with the applicable EQSs.

The development and implementation of an immission assessment procedure involves a series of normative and practical considerations that are closely interrelated:

- How to deal with multiple dischargers?

- How to deal with mixing zones?

- How to deal with temporal variations in effluent and system characteristics?

- How to deal with the exchange of substances between compartments?

- How to deal with mixture toxicity and multiple stressors?

- How to deal with uncertainty?

These normative issues do not necessarily apply to all discharges to the same extent. For conventional pollutants such as BOD, nitrogen and phosphate, major normative issues are waste load allocation among multiple discharges, tolerance of a formal mixing zone and dealing with temporal variations in effluent and system characteristics. For toxic pollutants such as metals and persistent organic pollutants (POPs), the exchange of substances between compartments, mixture toxicity and acute toxic effects within the mixing zone are also important.

Figure $2 \mathrm{~b}$ gives an impression of the possible implications of normative considerations on EQO-based effluent standards. Maximum permissible cadmium loads are calculated for the afore-mentioned pigment production plant, applying water quality models, input data and EQSs as prescribed by various regulatory agencies within Germany, the UK, the Netherlands and the USA. Differences run up to more than a factor of 30 .

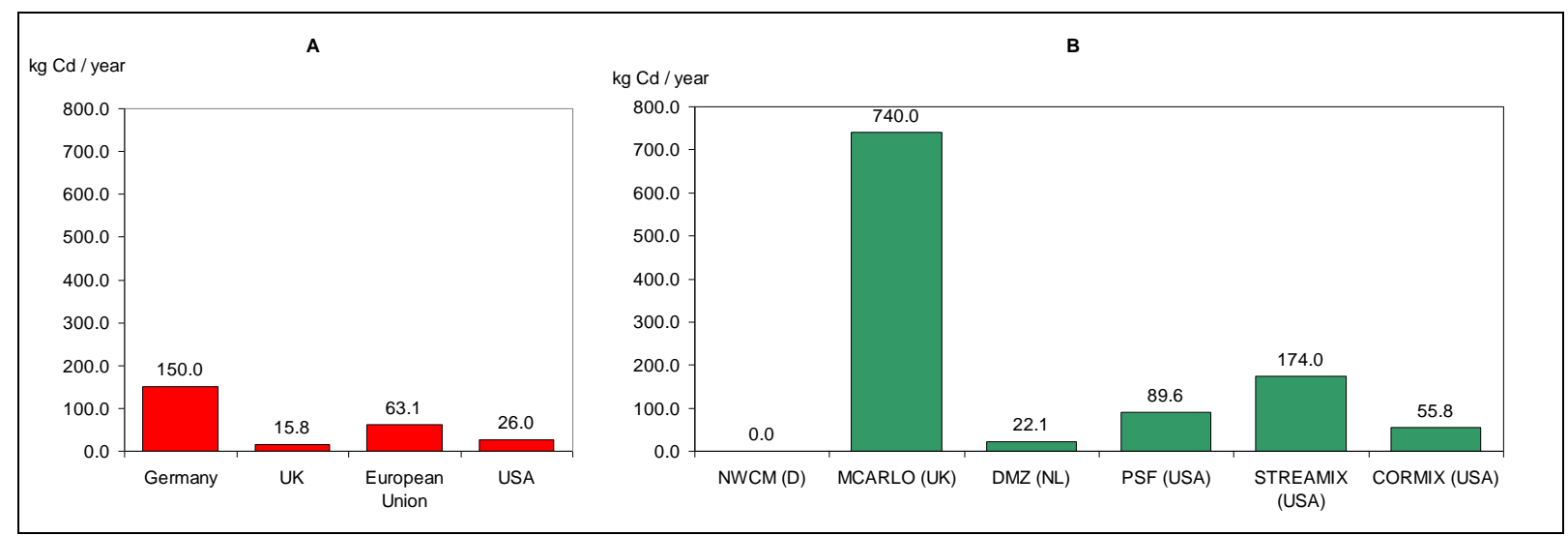


Figure 2. Comparison of permissible cadmium loads in various countries based: (a) technology-based standards, and (b) EQO-based standards. Ad, WAAR KOMEN CIJFERS FIGUUR VANDAAN?

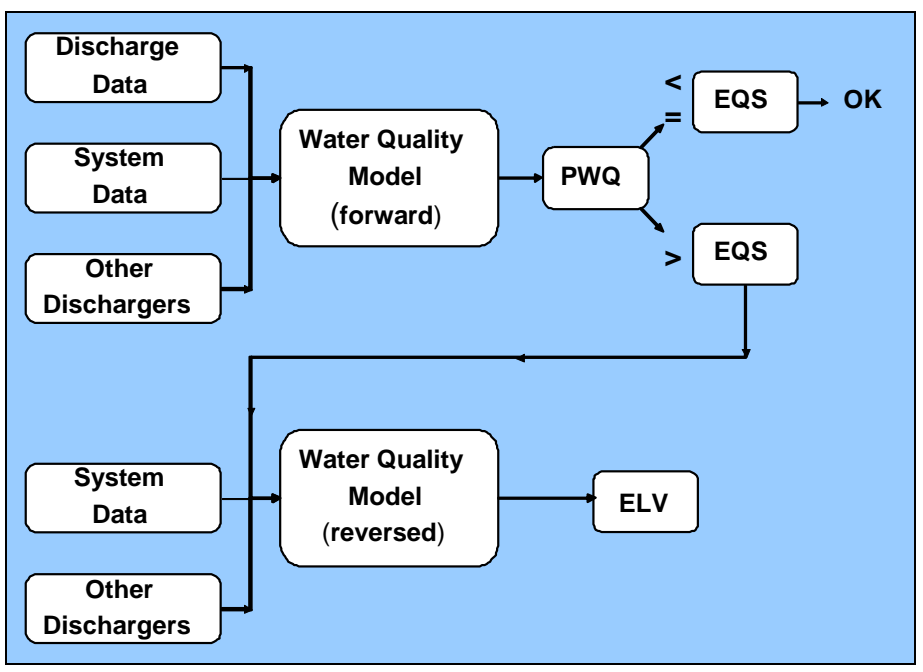

Figure 3. Schematic presentation of an immission assessment procedure

$(P W Q=$ Predicted Water Quality, EQS = Environmental Quality Standard, ELV = Emission Limit Value $)$

\section{Economical feasibility}

In economic terms, both approaches to effluent standard definition have pros and cons. First of all, the investment costs and operational costs for implementation and operating of an efficient EQO-based approach are generally higher than for the technology-based approach. Namely, the definition of EQSs requires a more complex approach, requiring more data, modeling and monitoring activities than a more straightforward technology-based approach. On the other hand, standards based on the EQO-based approach are directly linked to realizing certain economic use values for water (drinking water supply, fishery, biodiversity, etc.). The aim therein is to assure 'cost-effectiveness' (not stricter than necessary to realize certain water quality objectives and therewith certain use values of water and related economic benefits). When applying technology-based standards, these may in cases be too strict (incurring high costs) to realize the desired use values of water, or too loose, leading to situations where certain economic use values of water are not realized.

In view of these considerations, it should be evaluated on a case by case basis whether the EQObased approach, the technology-based approach or a combination of the two is more cost-effective and economically viable from a polluters perspective.

\section{Institutional capacity}

The institutional framework consists of the organizational conditions and procedures to ensure regulation of activities by all legal persons, to be carried out attending the principles, goals and policies adopted by the authorities. For regulation, instruments such as laws, decrees, resolutions, guidelines, standards, and economic instruments are needed to establish the sanctions and penalties to be applied by administrative or judiciary authorities when regulations fail to be complied with. In order to reduce pollution to the desirable level, the way of regulation is crucial. Legislation in itself provides the framework, but the means of regulation determines the exact effect on industry, in terms of response (D'Arcy and Frost, 2001). Command and control, market-based incentives, and voluntary action of the private sector, identify some of the most common regulatory options. Command and control regulation refers to direct standards, including quantitative limits on pollution levels and technology specification. Market-based incentives involve economic instruments such as taxes, fees, subsidies and marketable permits. In developing countries, new regulatory institutions are often unable to enforce conventional discharge standards at the factory level. Many regulators recognize that such standards are not costeffective because they require all polluting factories to toe the same line, regardless of abatement costs and local environmental conditions (Worldbank, 1999). However, market-based strategies do not specify the use of any particular pollution control technology: rather, they give polluters the flexibility and incentive to find the most cost-efficient means of achieving pollution control targets (O'Shea, 
2002). Economic instruments are therefore promising for developing countries in terms of affordable pollution control. An example of a financial incentive is charging polluters for every unit of their emissions. As results from programs in Colombia, China, and Philippines have shown, many managers opt for serious pollution control when they face steep, regular payments for emissions. And pollution charges not only cut emissions but generate public revenue as well-which in turn can support local efforts to control pollution (Worldbank, 1999).

Changing pollution behavior involves cultural transformations for which education and awareness rising are important prerequisites. In developing countries, public education regarding the sources and impacts of pollution provides a powerful lever for improving the lives of poor people. Citizens may suffer greatly from emissions even as industry's pollution intensity declines, but armed with good information, they can work with environmental agencies and elect political leaders willing to pressure factories to curb emissions.

A possible way of supplying information and raising awareness is the use of simple rating systems to publicly recognize factories that adhere to local and national pollution standards-and to train the communal eye on those that do not. By classifying factories based on their reported emissions, and widely broadcasting the results, regulators are enabling communities to identify serious polluters and pressure them to clean up. This channel for "informal" regulation has proven to be potent, even in cases where formal regulation is weak or absent. Indonesia and Philippines, in particular, have shown that such public disclosure programs can curb pollution at modest cost (Worldbank, 1999). The efficiency and effectiveness of pollution control and prevention strategies depend on the right combination of regulatory mechanisms, backed by adequate monitoring and surveillance and supported by sufficient capacity. The arising choices are strongly related to the chosen approach of pollution control.

\section{Practices in Western Europe and the USA}

The European Union (EU) regulates point source pollution through the Integrated Pollution Prevention and Control Directive (IPPC; EU, 1996) and the Water Framework Directive (EU, 2000). The IPPC Directive concentrates on the technology-based approach. BAT reference documents (BREFs) are produced by the European IPPC Bureau which Member States are required to take into account when determining best available techniques generally or in specific cases (EIPPCB, 2004). The WFD applies a combined approach. On the source side, it requires that all existing technology-driven source-based controls must be implemented as a first step. On the effects side, it requires that where the measures taken on the source side are not sufficient to achieve the applicable environmental quality objectives, additional measures are required.

The practical implementation of the technology- and EQO-based approaches differs considerably between EU member states (Haans et al., 1998). In the UK, both approaches are reasonably well elaborated, with ample documentation, support and scientific argumentation, at high data requirement and related costs. The guaranteed level of protection is high for substances for which EQSs apply, but it is limited in the absence of EQSs and a formalized mixing zone approach. The Netherlands recently introduced an immission test with moderate data requirements, a reasonable to high guaranteed level of protection and moderate estimated costs (DCIW, 2000). Documentation and users supports are still in the process of development. In Germany, the technology-based approach (BAT) is widely applied while the elaboration of the EQO-based approach is still limited. This leads to relatively low costs and low data requirement.

In the USA, this combined approach is laid down in the Clean Water Act. Effluent standards resulting from the technology-based approach are considered minimum requirements, and additional restrictions can result from an immission assessment procedure that involves the application of EQSs, a water quality (mixing zone) model and system characteristics. Technology-based effluent standards are laid down in codified regulations (Code of Federal Regulations). The EQO approach is well documented and supported (US-EPA, 1991). The data requirements of the procedures followed in the USA generally seem (very) high, as are the estimated costs. A high guaranteed level of protection rewards this approach.

\section{Practices in developing countries}

In most developing countries, the technology-based approach is applied, but a growing number of cases of the EQO-based approach are arising. In this study, some particular experiences with the EQO-based approach are studied. In the NIS countries (Box 1) the EQO-based approach is applied but not in a very effective manner. A case study in the Philippines (Box 2) shows that the main systems of the EQO-based approach are in place with respect to the Laguna de Bay area. 
It can be concluded from the case studies that the EQO-approach is applied with varying success in developing countries. The NIS-countries experience difficulties in setting realistic EQSs (too much EQSs or too stringent) and in enforcing the resulting effluent standards (lack of institutional capacity and/or lack of finance to maintain the system, system too complicated and/or effluent standards too stringent to enable enforcement). In the Philippines, the elements are in place but monitoring is still limited.

Case study 1: The NIS countries

The New Independent States (NIS) are the former USSR states in Eastern Europe, the Caucasus and Central Asia that have become independent, e.g., Ukraine, Kazakhstan and Kyrgyzstan. Water quality and discharge regulations in the NIS countries have largely remained unchanged since its establishment in the former Soviet Union. Companies require a discharge permit with effluent standards. Dispersion models are used to derive effluent standards that are compliant with EQSs that have been formulated for over 1,200 pollutants. These EQSs are determined exclusively on the basis of zero human exposure, without consideration of the technical or economic feasibility of compliance with them. The result is that EQSs and the resulting effluent standards are unrealistically strict (see Table 1)andards are used in practice (even though they are not envisioned in the law in some countries, as in Ukraine) with a goal of step-by-step attainment of EQSs. These limits are negotiable between the enterprise and regional environmental authorities on a case by case basis as a part of the permitting process. Environmental agencies have wide discretionary powers and few guidelines for negotiating the temporary limits, which creates space for corruption. Pollution charges in the NIS are levied on a large number of water pollutants. They are integrated with systems of enterprise-specific discharge limits specified in permits. The basic rates of the charges apply for discharges within the limits, whereas higher non-compliance fees (typically a multiple of the basic rate - from $20 \%$ in Uzbekistan to 15 -fold in Belarus) are levied on exceedances of the limits. The charge system has been very ineffective because of the huge number of pollutants involved, the limited monitoring facilities and the charges are too low to provide an incentive for reducing pollution. Enforcement of effluent standards is also a serious problem in the NIS countries because of unfeasible requirements, lack of political commitment, declining institutional capacity and lack of support of the court system. The existing NIS environmental quality monitoring systems suffer from the dispersion of monitoring functions, low quality of monitoring equipment and laboratories, and the lack of exchange and incompatibility of the data collected by different agencies.

Table 1. Comparison of selected EQSs for protection and support of fish life in Russia, Ukraine, Kazakhstan, and the EU (OECD, 2000).

\begin{tabular}{|l|c|c|c|c|}
\hline Parameter & Russia & Ukraine & Kazakhstan & $\begin{array}{c}\text { EU (78/659/EEC } \\
\text { for salmonid fish) }\end{array}$ \\
\hline BOD5 & $3-6$ & 2 & 3 & 3 \\
\hline Suspended solids, $\mathrm{mg} / \mathrm{l}$ & \multicolumn{2}{|c|}{ Background +0.75} & \multicolumn{2}{|c|}{25} \\
\hline Copper, $\mathrm{mg} / \mathrm{l} \mathrm{Cu}$ & 0.005 & 0.001 & 0.001 & 0.04 \\
\hline 7inn $\mathrm{mr} / 1 / 7 n$ & & & \\
\hline
\end{tabular}


Case study 2: Laguna de Bay, Philippines

Laguna de Bay is one of the largest freshwater lakes in Southeast Asia. It is located on the Philippine island of Luzon, and forms the eastern boundary of Metropolitan Manila. The Laguna Lake Development Authority (LLDA) oversees environmental compliance of companies around the Laguna de Bay. Any company or person that discharges liquid waste into the Laguna de Bay Region has to secure a permit from LLDA. Effluent standards are based on a national water quality classification scheme (DENR AO 34,1990$)$. This scheme contains five classes of fresh and inland waters (classes AA, A, B, C, and D) and four classes of marine and coastal waters (classes SA, SB, SC and SD. A specific set of effluent standards has been developed for each water quality class. These standards limit the maximum pollutant concentration in the effluent for 12 conventional parameters and 8 toxic substances (Peter, s.v.p. (in overleg met Ad) concreet tekstvoorstel formuleren Vragen voor Peter: Worden de lozingseisen strenger als de waterkwaliteit slechter wordt, of andersom? Antwoord: Dit is inderdaad het idee achter het systeem; Wat is de ratio achter dit systeem? Antwoord: Ik begrijp deze vraag niet; Worden er geen grenzen gesteld aan de totale lozingsvracht? Antwoord: Nee) . Besides effluent restrictions, companies are required to pay an annual fee for every unit of pollution they discharge. It is composed of a fixed fee that depends on the volumetric rate of discharge $(\$ 191-\$ 573)$ and a variable fee which is based on the pollution load. Violation of effluent standards is punishable by a Cease of Desist Order (CDO), which implies stoppage of the discharge plus a fine. Regulations are enforced by LLDA through an effluent and water quality monitoring program. For the initial 120-150 firms in the program, LLDA has assigned 35 staff to monitor each facility four times a year. As discharge fees are collected, LLDA will hire more staff and add more firms to the system. The ability of LLDA to fund the program adequately through discharge fees is what makes it unique in the Philippine government's effort to reduce pollution. Water quality of Laguna the Bay is monitored by LLDA on a regular basis. There are currently 13 monitoring stations

\section{A combined approach for developing countries}

Based on the theoretical study of technical, regulatory and institutional aspects as well as the experiences in the case studies, a summary of opportunities and constrains of both approaches as well as their combination was made (Table 2). The criteria used for comparison of the various responses are (i) protection of the environment, (ii) technical viability, (iii) economic feasibility, and (iv) institutional capacity requirements.

Main opportunities of the EQO-based approach are direct linkage to environmental requirements and sensitivity, and prescribing pollution control measures will not be stricter than necessary. Next to this, the financial burden of measures may be less while at the same time flexibility is created for taking into account ability-to-pay. The main constraint, especially for developing countries, is the fact that it is technically and institutionally more complicated to implement and operate, implying also that the system will be more costly. For example, to derive EQSs sufficient biological effects data are required. Main opportunities of the technology-based approach lie therein that lower requirements regarding technical and institutional capacity are needed, which might make the system less complicated to implement and operate. ELV's are based on chemical data that are relatively easy to acquire. Consequently, it is less costly from an institutional perspective (note: the cost to polluters may be higher, making the overall cost of implication actually higher). Main constraints are that the approach does not always guarantee that specific environmental objectives will be met. In other cases the required level of pollution control measures might be high, which in turn might lead to high costs for polluters and a low affordability among dischargers.

The study has concluded that it is possible to define a combined approach which partly offsets some of the constraints of both approaches, while the key opportunities are preserved. At the basis of this approach is a set of technology-based standards that reflects Best Available Technology Not Entailing Excessive Costs (BATNEEC) to prevent avoidable pollution. An exception is made for persistent substances for which effluent standards should always be based on BAT. In addition, water quality should be checked against a set of clear and adequate EQSs. Where limits are breached, more 
stringent effluent standards should be prescribed. For developing countries however, it is recommended that this water quality-based approach should in first instance be applied only in selected priority areas, i.e., pristine and highly polluted areas, or areas with important economic use values or public health risks. This will reduce the institutional capacity requirements, while still ensuring sufficient protection of the environment. To account for the limited resources of the developing countries, the BATNEEC-standards may be less stringent than the BAT-standards used in developed countries if the carrying capacity of the receiving water body is sufficient (e.g., a large water body with limited wastewater influent). In time, with institutional, technical and financial capacity increasing, BATNEEC standards could be upgraded to BAT and the EQO-approach could be implemented in the entire country. The recommended approach will reduce the technical and institutional complexity concerned with a mainstream water quality-based approach, while still ensuring sufficient protection of the environment.

Table 2. Opportunities and constraints of the water quality-based, technology-based and combined approaches.

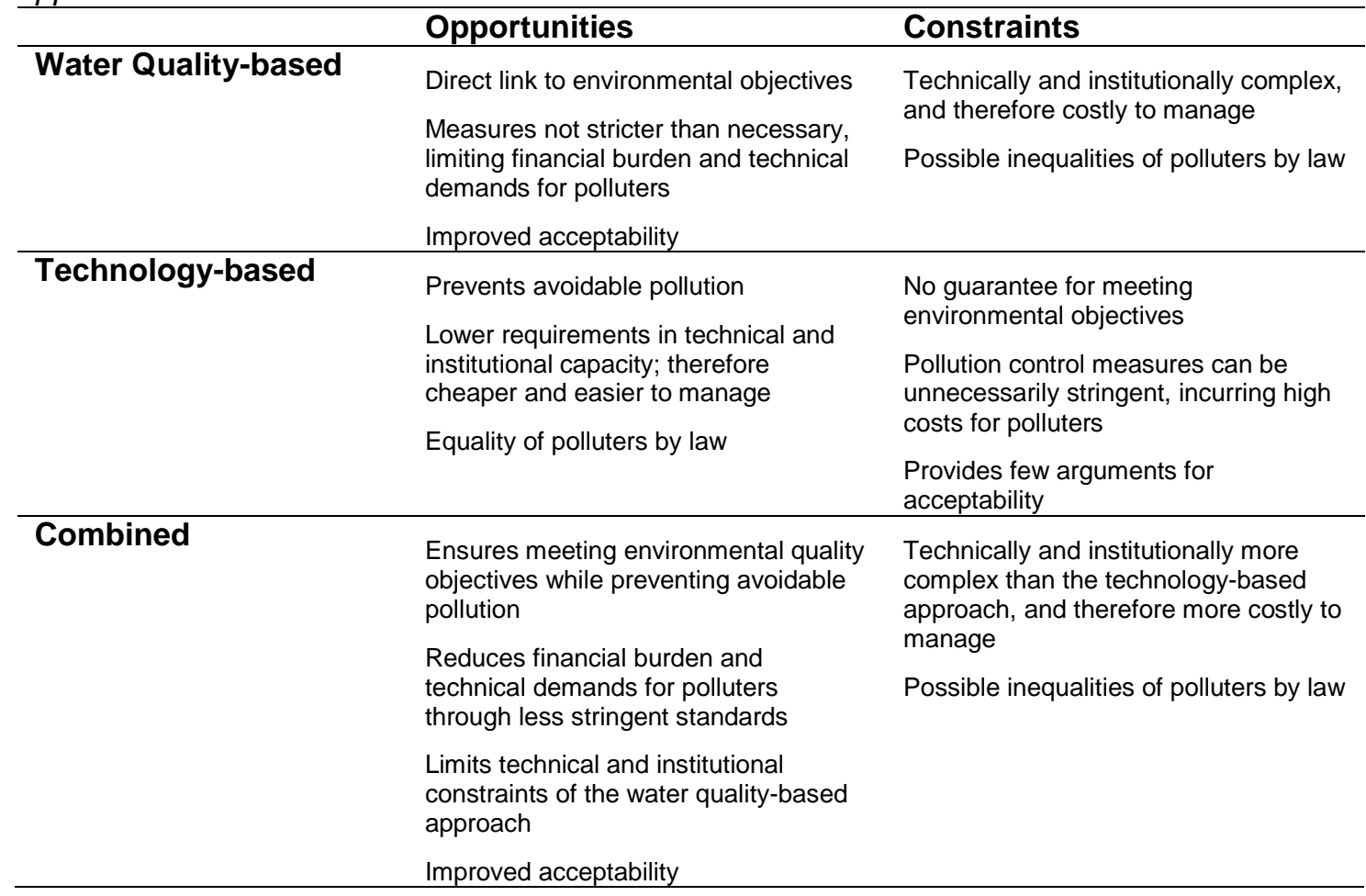

Finally, it should be noted that this study focussed on point sources. However, diffuse sources are becoming increasingly important in the overall pollution problem of developing countries and require approaches that differ from the conventional means of practice (D'Arcy and Frost, 2001). For example, marketable permits allow flexible pollution control of point sources, but can also be used in relation to diffuse sources in the shape of land-use permits (O'Shea, 2002).

\section{References}

D'Arcy, B. and A. Frost (2001). The role of best management practices in alleviating water quality problems associated with diffuse pollution. The Science of the Total Environment 265, 359-367

DENR AO 34 (1990). Department of Environment and Natural Resources, Administrative Order 34, The Philippines.

DCIW (Dutch Commission for Integrated Water Management) (2000). Emissie-immissie. Prioritering van bronnen en de immissietoets. Commissie Integraal Waterbeheer(CIW), Den Haag (in Dutch). 
EIPPCB (2004). IPPC BREF outline and guide. European Integrated Pollution Prevention and Control Bureau at http://eippcb.jrc.es/.

EU (1996). Council Directive 96/61/EC of 24 September 1996 concerning integrated pollution prevention and control.

EU (2000). Council Directive 2000/60/EC, Establishing a framework for community action in the field of water policy. European Commission PE-CONS 3639/1/100 Rev 1, Luxemborg.

Grossman, G.M. and Krueger, A.B. (1992). Environmental Impacts of a North American Free Trade Agreement. Woodrow Wilson School, Princeton, NJ.

Haans, J.L.M., Leuven, R.S.E.W. and Ragas A.M.J. (1998). Immission assessment procedures for discharge permitting. In: Nienhuis, P.H., Leuven, R.S.E.W. and Ragas, A.M.J. (eds.). New concepts for sustainable management of river basins. Backhuys Publishers, Leiden, pp. 179-189.

Jirka, G.H., Bleninger, T., Burrows, R. and Burrows, R. (2004). Environmental Quality Standards in the EC-Water Framework Directive: Consequences for Water Pollution Control for Point Sources European Water Management Online 2004/01. http://www.ewaonline.de/journal/online.htm

Jirka, G. H. and Summer, W. (1992). The expert system CORMIX for water quality management and hydrodynamic mixing zone analysis. In: Gayer, J., Starosolszky, Ö., and Maksimovic, C. (eds). Hydrocomp '92. Water Resources Research Centre (VITUKI), Budapest, pp. 269-277.

Konterman, I., Scheren, P., Leuven, R.S.E.W., Ragas, A.M.J., Lubberding, H., Niebeek, G. and Stortelder, P. (2003). Environmental Quality Objective Approach to Effluent Standards Definition. A useful approach within the Developing Countries context? Royal Haskoning, Nijmegen.

Kraemer, R.A. (ed) (1996). Approaches to pollution control and the protection of the aquatic environment. Länderarbeitsgemeinschaft Wasser (LAWA), Environment Agency, Bristol.

OECD (1996). Workshop on environmental requirements for industrial permitting. Reference guide. Organisation for Economic Cooperation and Development (OECD), Paris.

O'Shea, L. (2002). An economic approach to reducing water pollution: point and diffuse sources. The Science of the Total Environment 282/283, 49-63

Ragas, A.M.J. (2000). Uncertainty in environmental quality standards. Ph D thesis, University of Nijmegen, Nijmegen.

Ragas, A.M.J. and Leuven, R.S.E.W (1999). Modelling of water quality-based emission limits for industrial discharges in rivers. Water, Science \& Technology 39 (4): 185-192.

Ragas, A.M.J., Haans, J.L.M. and Leuven, R.S.E.W. (1997). Selecting water quality models for discharge permitting. European Water Pollution Control 7 (5): 59-67

Rothman D.S. and De Bruyn, S.M. (1998). Probing into the environmental Kuznets curve hypothesis. Ecological Economics 25, 143-145.

Scheren, P.A., Kroeze, C., Janssen, F.J., Hordijk, L., Ptasinski, K.J. (2004). Integrated Water Pollution Assessment of the Ebrié Lagoon, Ivory Coast, West Africa, Journal of Marine Systems, 44, 1-17.

Scheren, P.A., Ibe, A.C. (1999). Environmental Pollution in the Gulf of Guinea - A Regional Approach, In The Gulf of Guinea Large Marine Ecosystem (McGlade, J., Sherman, K., Korangteng, K. and Curry, P. Eds.) Elsevier Publishers.

Scheren, P.A., Zanting, H.A., Lemmens, A.M. (1998). Estimation of Water Pollution in Lake Victoria: Application and Elaboration of the Rapid Assessment Methodology, Journal of Environmental Management, 58, 235-248. 
Smeets, E. and Weterings, R. (1999). Environmental indicators: Typology and overview. European Environment Agency, Copenhagen, p. 4-11.

Stortelder, P. B. M. and Van de Guchte, C., 1995. Hazard assessment and monitoring of discharges to water: Concepts and trends. European Water Pollution Control 5 (4), 41-47.

United Nations (1992). Agenda 21. Adopted during the Conference on Environment and Development on 14 June 1992. http://www.un.org/esa/sustdev/documents/agenda21/.

United Nations (2002). Report of the World Summit on Sustainable Development, Johannesburg, South Africa, 26 August-4 September 2002. United Nations publication A/CONF.199/20*, New York.

US-EPA (1991). Technical support document for water quality-based toxics control. United States Environmental Protection Agency, Office of Water, Report EPA/505/2-90-001, Washington DC.

Whitehouse, P. (2001). Measures for Protecting Water Quality: Current Approaches and Future Developments. Ecotoxicology and Environmental Safety 50, 115-126

Worldbank (1999). Greening Industry:New Roles for Communities,Markets, and Governments. Development Research Group, October 1999, ISBN 0-1 9-521127-3, World Bank, Washington DC. 